\title{
Whole-genome sequences shed light onto demographic history and contemporaneous genetic erosion of free-ranging jaguar (Panthera onca) populations
}

Gustavo Lorenzana $^{1}$, Henrique Figueiró ${ }^{1}$, Christopher Kaelin $^{2}$, Greg Barsh ${ }^{2}$, Jeremy Johnson $^{3}$, Elinor Karlsson ${ }^{3}$, Ronaldo Morato ${ }^{4}$, Denis Sana ${ }^{5}$, Laury Cullen ${ }^{6}$, Joares May Jr. $^{7}$, Edsel Moraes Jr. ${ }^{8}$, Daniel Kantek ${ }^{9}$, Leandro Silveira ${ }^{10}$, William Murphy ${ }^{11}$, Oliver Ryder $^{12}$, and Eduardo Eizirik ${ }^{1}$

\author{
${ }^{1}$ PUCRS \\ ${ }^{2}$ Stanford University \\ ${ }^{3}$ Broad Institute Harvard \\ ${ }^{4}$ CENAP-ICMBio \\ ${ }^{5}$ Instituto Pro-Carnivoros \\ ${ }^{6}$ Instituto de Pesquisas Ecológicas \\ ${ }^{7}$ UNISUL \\ ${ }^{8}$ Instituto Biotrópicos \\ ${ }^{9} \mathrm{ICMBio}$ \\ ${ }^{10}$ Conservation Fund/Instituto Onça-Pintada \\ ${ }^{11}$ Texas A\&M University College Station \\ ${ }^{12}$ San Diego Zoo's Institute for Conservation Research
}

March 12, 2021

\begin{abstract}
The vast amount of data contained in a single genome represents a detailed record of past events in that lineage and may forecast its evolutionary potential in the face of environmental changes. Here we employed whole-genome sequence (WGS) data to infer the demographic history and assess signals of recent inbreeding in jaguar (Panthera onca) populations. We analyzed whole genomes from 13 individuals (nine of which are reported here for the first time) sampled in seven different biomes across the species' range, including its northernmost extreme in the Mexico/USA border region. We modelled demographic history using the PSMC method, and analyzed long runs of homozygosity $(\mathrm{ROH})$ to assess signals of population bottlenecks and inbreeding. PSMC plots were very consistent among individuals, indicating that the jaguar lineage had an effective population size of up 100,000 individuals ca. 1 million years ago, then sharply declined and rebounded during the Late Pleistocene, followed by a more gradual decline in the last 40,000 years. This decline was more pronounced in the North/Central American genomes, likely reflecting population bottlenecks during the south-north colonization towards the edge of the species' current range. The $\mathrm{ROH}$ analysis revealed a relatively small burden for most jaguars, indicating a recent history of outbreeding and largescale connectivity among regional populations. However, northern range-edge individuals and those from severely fragmented populations showed signals of recent bottlenecks and, in the latter case, inbreeding. Our results illustrate the power of WGS data to survey and monitor the genetic erosion triggered by anthropogenic habitat fragmentation.
\end{abstract}

\section{Hosted file}


Lorenzana_Draft_v8_MEC.pdf available at https://authorea.com/users/400999/articles/513287whole-genome-sequences-shed-light-onto-demographic-history-and-contemporaneous-geneticerosion-of-free-ranging-jaguar-panthera-onca-populations 